\title{
A stereotaxic map of brainstem areas critical for locomotor responses in a novel environment
}

\author{
ROBERT THOMPSON and JOSEPH E. LEDOUX \\ Louisiana State University, Baton Rouge, Louisiana 70803
}

\begin{abstract}
Latency to locomote from an illuminated compartment into a dark compartment was recorded in brain-damaged and control rats. The distribution of lesions sustained by those rats failing to enter the dark compartment within $10 \mathrm{~min}$ was plotted on the Massopust atlas. Clearly represented within the resulting map were those brainstem areas occupied by nigro-striatal and pallidofugal pathways.
\end{abstract}

In connection with a series of experiments on the rodent's preference for a dark compartment over an illuminated compartment (Thompson \& LeDoux, 1974; unpublished report), we observed that some rats with bilateral injuries to a circumscribed region of the brainstem (those areas occupied by nigro-striatal and pallidofugal pathways) failed to show any locomotor movement within a novel environment. This observation is of considerable interest since no other bilateral lesions placed elsewhere within the tel-, di-, mes-, or metencephalon yielded this dramatic effect. By virtue of this striking degree of localization, a separate report of these results seemed warranted.

\section{METHOD}

Adult male albino rats of the Wistar strain were used. The majority sustained bilateral cortical or subcortical lesions 6 to 20 days prior to testing. The size of the lesions investigated in this experiment was comparable to those reported in a recent study which also canvassed many different cortical and subcortical structures with lesions (Thompson, 1974). During the postsurgical period, each subject was handled and its behavior periodically observed on a black masonite table. Food and water were available at all times.

The apparatus consisted of a two-compartment box which has been fully described elsewhere (Thompson \& LeDoux, 1974). The test consisted of placing the subject into the illuminated compartment and observing the subject for $10 \mathrm{~min}$. The latency to enter the dark compartment (scored when the subject placed all four feet within the threshold), the number of exits from the dark compartment, and the total amount of time spent in the dark compartment were recorded. (Only the results concerning the latency measure will be discussed).

\section{RESULTS}

Table 1 presents the mean latency scores for all groups and the percentage of subjects from each group that failed to enter the dark compartment during the 10-min observation period.

The various groups of brain-damaged subjects fall neatly into one of four different categories. The first

This research was supported in part by a grant from the Graduate Council on Research, Louisiana State University.
Table 1

Mean Latency Scores for All Groups and Percentage of Rats from Each Group that Failed to Enter the Dark Compartment

\begin{tabular}{|c|c|c|c|}
\hline Group & $\mathrm{N}$ & $\begin{array}{c}\text { Mean } \\
\text { Latency (sec) }\end{array}$ & $\begin{array}{l}\text { Fail- } \\
\text { ures }\end{array}$ \\
\hline Control & 20 & 54.9 & 0 \\
\hline Blind & 12 & 47.3 & 0 \\
\hline Olfactory bulb & 5 & $3.0 *$ & 0 \\
\hline Anterior neocortex & 4 & 12.2 & 0 \\
\hline Posterior neocortex & 5 & 27.8 & 0 \\
\hline Decorticate & 14 & $14.9 *$ & 0 \\
\hline Caudate nucleus & 4 & 20.5 & 0 \\
\hline Globus pallidus & 7 & $370.3^{*}$ & $57.1 * *$ \\
\hline Cingulate cortex & 9 & 24.6 & 0 \\
\hline Hippocampus & 9 & 95.6 & 11.1 \\
\hline Septal area & 7 & 80.8 & 0 \\
\hline Amygdala & 7 & 24.6 & 0 \\
\hline Anterior thalamus & 5 & 24.6 & 0 \\
\hline Ventromedial thalamus & 5 & $482.6 *$ & $80.0 * *$ \\
\hline Dorsomedial thalamus & 7 & 36.3 & 0 \\
\hline Lateral thalamus & 5 & 130.0 & 0 \\
\hline Ventral thalamus & 5 & 40.4 & 0 \\
\hline Posteromedial thalamus & 12 & $351.5^{*}$ & $41.7 * *$ \\
\hline Anteromedial hypothal. & 8 & 96.2 & 12.5 \\
\hline Anterolateral hypothal. & 6 & 76.2 & 0 \\
\hline Posteromedial hypothal. & 11 & $286.8 *$ & $27.3 * *$ \\
\hline Posterolateral hypothal. & 8 & $474.4^{*}$ & $62.5 * *$ \\
\hline Internal capsule & 3 & $600.0^{*}$ & $100.0 * *$ \\
\hline Subthalamus & 10 & $126.6 *$ & 0 \\
\hline Ventral tegmental area & 7 & $441.3 *$ & $71.4 * *$ \\
\hline Prerubral area & 4 & $353.2 *$ & $50.0 * *$ \\
\hline Red nucleus & 4 & $266.5^{*}$ & 0 \\
\hline Substantia nigra & 8 & $275.4 *$ & $25.0 * *$ \\
\hline Central tegmental area & 7 & 66.0 & 0 \\
\hline Superior colliculus & 6 & 18.0 & 0 \\
\hline Inferior colliculus & 3 & 22.3 & 0 \\
\hline Rostral mes. ret. form. & 8 & $317.9 *$ & $25.0 * *$ \\
\hline Dorsal mes. ret. form. & 5 & 37.2 & 0 \\
\hline Lateral mes. ret. form. & 6 & 24.3 & 0 \\
\hline Caudal mes. ret. form. & 5 & 94.0 & 0 \\
\hline Pontine ret. form. & 6 & 53.5 & 0 \\
\hline Cerebellum & 4 & $360.0^{*}$ & 0 \\
\hline
\end{tabular}

${ }^{*} p<.05$ (Mann-Whitney U test)

${ }^{* *} p<.05$ (Fisher exact probability test)

category would consist of those groups showing significantly longer latency scores than the controls and containing subjects that failed to enter the dark 


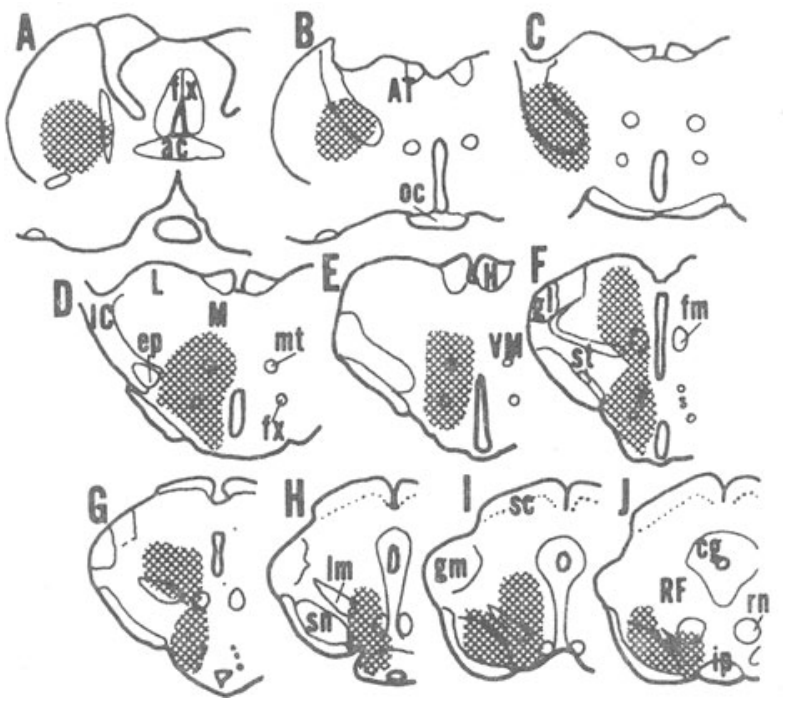

Figure 1. Critical area (cross-hatched) for initiation of locomotor movement shown at $\mathbf{1 0}$ frontal levels derived from the Massopust (1961) atlas. (Abbreviations: ac $=$ anterior commissure; $\mathbf{A T}=$ anterior thalamus; $\mathrm{cg}=$ central gray; $\mathrm{ep}=$ entopeduncular nucleus; $\mathbf{f m}=$ habenulopenduncular tract; $\mathbf{f x}=$ fornix column; gl = lateral geniculate nucleus; $\mathrm{gm}=$ medial geniculate nucleus; $\mathbf{H}=$ habenula; $\mathbf{I C}=$ internal capsule; ip = interpeduncular nucleus; $L=$ lateral thalamus; $I m=$ medial lemniscus; $M=$ medial dorsal thalamus; $m t=$ mamillothalamic tract; oc = optic chiasma; $\mathbf{R F}=$ midbrain reticular formation; $\mathbf{r n}$ $=$ red nucleus; $\mathbf{s c}=$ superior colliculus $; \mathrm{sn}=$ substantia nigra; $\mathbf{s t}=$ subthalamic nucleus; $\mathbf{V M}=$ ventromedial thalamus.)

compartment. The second category would consist of those groups showing significantly longer latency scores than the controls but devoid of subjects failing to enter the dark compartment. The third category would consist of those groups that did not differ significantly from the controls in latency scores and the last category would consist of those groups showing significantly shorter latency scores than the controls.

Mapping the critical area for this deficit in the initiation of locomotor movement within a novel environment was based upon the distribution of lesions sustained by those subjects falling within the first category that failed to enter the dark compartment. Figure 1 depicts this critical area which will be named, for convenience, the "critical locomotor initiating area" (CLIA). It will be noted that the caudal extent of the CLIA embraces mainly the subrubral (ventral tegmental) area and the substantia nigra (Figure $1 \mathrm{~J}$ ). At more rostral levels, the CLIA appears to bifurcate, one branch coursing into the posterior thalamus and the second into Forel's fields and the posterior hypothalamus (Figure 1F). Further rostrally, the CLIA converges in a region surrounding the mamillothalamic tract and fornix column (Figure 1D) and then passes laterally into the internal capsule (Figure 1C) and subsequently into the globus pallidus (Figure 1A).

\section{DISCUSSION}

The anatomical structures making up the CLIA are generally in agreement with earlier findings on the rat (Balagura, Wilcox, \& Coscina, 1969; Robinson \& Whishaw, 1974; Smith, 1970; Vanderwolf, 1971) and closely correspond to pathways originating within the substantia nigra (Hedreen, 1971; Ungerstedt, 1971) and globus pallidus (Morgane, 1961).

It is important to note that lesions of the CLIA not only impair initiation of movement but may impair eating and drinking behaviors (Morgane, 1961; Ungerstedt, 1971), pain-escape performance (Runnels \& Thompson, 1969), and retention of various learned tasks (Thompson, 1974). This raises the question concerning the extent to which the foregoing disorders are products of a common disturbance. In discussing the nigro-striatal dopaminergic system (which forms a part of the CLIA), Ungerstedt (1971) has suggested that a reduction in general arousal levels may constitute the common disturbance. We are led to speculate that the entire CLIA may serve arousal functions, especially in view of the conspicuous overlap between the rostral portions of the ascending reticular activating system (Starzl, Taylor, \& Magoun, 1951) and the CLIA.

\section{REFERENCES}

Balagura, S., Wilcox, R. H., \& Coscina, D. V. The effect of diencephalic lesions on food intake and motor activity. Physiology and Behavior. 1969, 4, 629-633.

HedReEN, J. C. Separate demonstration of dopaminergic and non-dopaminergic projections of substantia nigra in the rat. Anatomical Records, 1971, 169, 338(abstract).

Massopust, L. C. Stereotaxic atlases: A. Diencephalon of the rat. In D. E. Sheer (Ed.), Electrical stimulation of the brain. Austin: University of Texas Press, 1961.

Morgane. P. J. Alterations in feeding and drinking behavior of rats with lesions in globi pallidi. American Journal of Physiology, 1961, 201, 420-428.

Robinson, T. E., \& Whishaw, I. Q. Effects of posterior hypothalamic lesions on voluntary behavior and hippocampal electroencephalograms in the rat. Joumal of Comparative and Physiological Psychology, 1974, 86. 768-786.

Runnels, P., \& Thompson, R. Hypothalamic structures critical for the performance of a locomotor escape response in the rat. Brain Research, 1969, 13, 328-337.

Smith, A. M. Deficits in conditioned movement and visual discrimination following rubral area lesions in the rat. Physiology and Behavior. 1970, 5. 893-898.

Starzl. T. E., Taylor, C. W., \& Magoun, H. W. Ascending conduction in reticular activating system, with special reference to the diencephalon. Journal of Neurophysiology, 1951. 14. $461-477$.

Thompson, R. Localization of the "maze memory system" in the white rat. Physiological Psychology, 1974, 2, 1-17.

Thompson, R., \& LeDoux, J. E. Common brain regions essential for the expression of learned and instinctive visual habits in the albino rat. Bulletin of the Psychonomic Society, 1974, 4. 78-80.

UNGERSTEDT, U. Adipsia and aphagia after 6-hydroxydopamine induced degeneration of the nigro-striatal dopamine system. Acta Physiologica Scandinavica, 1971. Supplementum 367. 95-122.

VANDERWOLF, C. H. Limbic-diencephalic mechanisms of voluntary movement. Psychological Review, 1971, 78, 83-113.

(Received for publication June 13, 1975.) 